\title{
Patient Safety, Adverse Healthcare Events and Near-Misses in Obstetric Care -A Systematic Literature Review
}

\author{
Elisabeth Severinsson ${ }^{1}$, Megumi Haruna ${ }^{2}$, Maria Rönnerhag1,3, Ingela Berggren ${ }^{3}$ \\ ${ }^{1}$ Centre for Women's, Family and Child Health, Faculty of Health Sciences, Buskerud \& Vestfold University \\ College, Kongsberg, Norway \\ ${ }^{2}$ Department of Midwifery and Women's Health, Division of Health Sciences \& Nursing, Graduate School of \\ Medicine, The University of Tokyo, Tokyo, Japan \\ ${ }^{3}$ Department of Health Sciences, University West, Trollhättan, Sweden \\ Email: *elisabeth.severinsson@hbv.no
}

Received 18 November 2015; accepted 26 December 2015; published 29 December 2015

Copyright (C) 2015 by authors and Scientific Research Publishing Inc.

This work is licensed under the Creative Commons Attribution International License (CC BY).

http://creativecommons.org/licenses/by/4.0/

(c) (i) Open Access

\section{Abstract}

Systematic development of a patient safety culture is necessary because lack of quality care leads to human suffering. The aim of this review was to identify evidence of obstetric adverse events (AEs) and near-misses in the context of patient safety. We conducted a search of the published literature from Europe, Australia and the USA in the following databases: Cinahl, Cochrane, Maternity and Infant Care, Ovid, Pro-quest and PubMed, guided by PRISMA procedures. A total of 427 studies were screened, 15 full papers retrieved and nine studies included in the final thematic analysis. The selected papers address a broad spectrum of adverse patient safety events in obstetric care. The themes that emerged were: type of AEs, near-misses and their consequences, strategies to support and improve Patient Safety (PS) and domains related to the WHO Patient Safety competence outcomes. The findings of the first theme were grouped into the following categories: healthcare professionals' perspectives on ethical conflicts, attributing blame and responsibility, and patients' perspectives on lack of trust and involvement, as well as medication errors. The second theme, strategies to support interventions to improve PS, was based on two sub-themes: communicating effectively and gaining competence by learning from adverse events, while the third theme was domains related to the WHO Patient Safety competence outcomes. In conclusion, few studies have examined strategies for managing AEs despite the existence of programmes that target the implementation of changes, such as improved teamwork training. In addition to exploring strategies to make safety a priority for patients and healthcare professionals, it is of the utmost importance to improve communication with patients and between professionals in order to maintain and enhance safety. Efforts by organizations and individuals to continuously develop knowledge

${ }^{*}$ Corresponding author.

How to cite this paper: Severinsson, E., Haruna, M., Rönnerhag, M. and Berggren, I. (2015) Patient Safety, Adverse Healthcare Events and Near-Misses in Obstetric Care-A Systematic Literature Review. Open Journal of Nursing, 5, 1110-1122. http://dx.doi.org/10.4236/ojn.2015.512118 
about the risk of AEs and the use of best practice guidelines are also essential.

\title{
Keywords
}

\author{
Maternal Care, Adverse Obstetric Healthcare Events, Patient Safety, Near-Misses
}

\section{Introduction}

Patient Safety (PS) in obstetric healthcare has been researched in terms of learning needs and explored in order to strengthen safety [1]. Our definition of patient safety practices includes system, organisational and behavioural interventions, both individually and in combination [2]. Not surprisingly, there is variation in the definition of PS. The World Health Organisation (WHO) defines patient safety practices as processes or structures that reduce the probability of adverse events (AEs) caused by exposure to the healthcare system across a range of diseases and procedures ([3], p. 1). In an effort to report the domains that were necessary for the implementation of PS practices, Taylor et al. [4] focused on safety culture, teamwork and leadership, structural and organisational aspects such as size, organizational complexity and financial status, in addition to external factors including PS regulations and the availability of implementation and management tools, such as training resources and organisational incentives. Building a safety culture is crucial for reducing the number and severity of errors, for which learning through PS incidents is an important method [5]. Another approach to PS can be found in the study by Hasley [6], who reports that decision support may enhance PS by helping clinicians to improve patient evaluation, assessment, and treatments. The author thereby includes important aspects that provide best practice guidelines at critical decision points, thus preventing errors. This was in line with Madden and Milligan [7], who recommended maternity care interventions intended to enhance the health of mother and child by preventing or reducing complication and their consequences. The authors highlighted the need to report near-misses, because such events constitute a valuable learning experience and should be identified, reported and scrutinised as part of supervision. In accordance with the Department of Health (DoH) [8], healthcare near-misses are defined as an event arising during clinical care that fails to develop further, whether or not as a result of compensating action. According to Say et al. ([9], p. 289), the definition of maternal near-miss is "A woman who nearly died but survived a complication that occurred during pregnancy, childbirth or within 42 days of termination of pregnancy". The authors presented three useful approaches for identifying maternal near-miss: clinical criteria related to a specific disease entity, intervention-based criteria and organ system dysfunction-based criteria. The WHO systematic review of maternal morbidity and mortality aimed at determining the worldwide prevalence of severe acute maternal morbidity, also known as a near-miss, [9] was of great relevance to this review. The authors conclude that there is a need to introduce uniform criteria to standardise the classification of severe acute maternal morbidity. Khan et al. [10] conducted a review to determine the distribution of causes of maternal death. The findings of 34 datasets were included in the analysis, which revealed that haemorrhage was the leading cause of death followed by hypertensive disorders and sepsis.

The goal of the WHO Safe Childbirth Checklist Collaboration is to improve the health of mothers and neonates [11] by initiating a process of agreeing on a definition and developing a uniform set of identification criteria for maternal near-miss. The Quality Maternal and Newborn Care, on which the Lancet Midwifery Series is based, highlights what women need and want during pregnancy and childbirth [12]. Ten Hoope-Bender et al. [13] proposed three priority research areas and outlined the need for state investment in midwives as well as in their work environment, education, regulation, and management, all of which can improve the quality of care. However, despite the fact that a link between midwifery and quality of care in terms of efficient use of resources and improved outcomes has been reported, research on maternal care and PS is underdeveloped. Existing research on AEs, which should constitute a cornerstone of safety analysis and improvement, is scare [14]. Although healthcare interventions exist, the understanding of how to implement them in practice is lacking. Several programmes have been developed to address unacceptable levels of preventable AEs in maternity care. For example, Régo et al. [15] suggested an inter-professional resource management training programme to eliminate communication failure between medical and midwifery staff.

This research is part of a wider international project on PS based on recommendations by the WHO [16]-[19]. 
The ongoing research has an implementation approach focusing on how to operationalize and achieve evidence-based and efficacious safe care, as well as which factors contribute to or hinder the success of such an intervention, and why this is the case [20]. The WHO PS areas adopted in the research programme are: PS and health services, system development, knowledge of and learning about PS, PS awareness and identifying PS gaps at all levels of the health service. The definitions of PS adopted in this project are related to the dynamic system of healthcare and focus on the interaction of several elements, as well as the fact that incidents result from ineffective communication between the actors involved. Thus, preventing unnecessary injury that causes physical or psychological harm to a patient is of the utmost importance. As an AE is a difficult situation for a patient, it is necessary to focus on investigating the evidence in obstetric care.

\section{Aim}

The aim of this review was to identify evidence of obstetric AEs and near-misses in the context of PS. The review questions were: What types of healthcare $\mathrm{AE}$ and near-misses were reported? And what intervention was implemented to prevent AEs and support the patients, their family members, and the professionals involved?

\section{Methods}

\subsection{Search Strategy, Data Sources, and Screening}

The first author recruited a specialized librarian to discuss the keywords to be employed in identifying peer-reviewed articles on the topic. The first search included five databases: Cinahl, Maternity and Infant Care, Ovid, Pro-quest and PubMed using the following keywords: patient safety, adverse healthcare events, maternal health services, obstetric and pregnancy complications. A second search was conducted in August 2015 in which the Maternity and Infant Care, Ovid, Pro-quest and PubMed databases were screened for the last 10 years using the keywords: patient safety, near-misses, and pregnancy in various combinations with misses OR adverse outcome OR effect* OR event*.

\subsection{Criteria, Data Extraction and Included Articles}

The inclusion criteria were original peer reviewed studies in the English language published between 2005 and 2015. The exclusion criteria were studies about abortion, maternal obesity, antenatal heart disease, diabetes in pregnancy, intimate partner violence, homebirth, programmes that did not include the keyword "patient safety", and studies from developing countries. Duplicates were excluded, resulting in nine articles (Figure 1). We reviewed the selected articles by focusing on their author, title, country, research aim and questions, subjects, setting, method/design, data analysis, type of evidence related to healthcare AEs, and near misses, as well as interventions to support the persons involved. All authors on the research team were involved in assessing the data extraction and interpretation of the content of the included papers (Table 1).

\subsection{Quality Review}

The selected papers were screened and their quality evaluated using a step-by-step method guided by PRISMA procedures. We focused on two broad review questions: first, types of healthcare AEs and near-misses, and second, which interventions were implemented to prevent new AEs and support the patients, their family members, and the professionals involved.

\subsection{Thematic Analysis and Interpretation of the Included Articles}

The findings were analysed in stages by means of a thematic empirical synthesis based on the aim of the study. Initial descriptions of the included articles were formulated. Relationship patterns were explored to identify themes and sub-themes. In addition, an interpretation of the consequences of AE's and near-misses was developed and strategies to support interventions aimed at improving PS were related to the WHO's Patient Safety Competence Outcomes (Table 2).

\section{Results}

The search strategy yielded 427 hits. Figure 1 describes the selection of the nine included articles. 


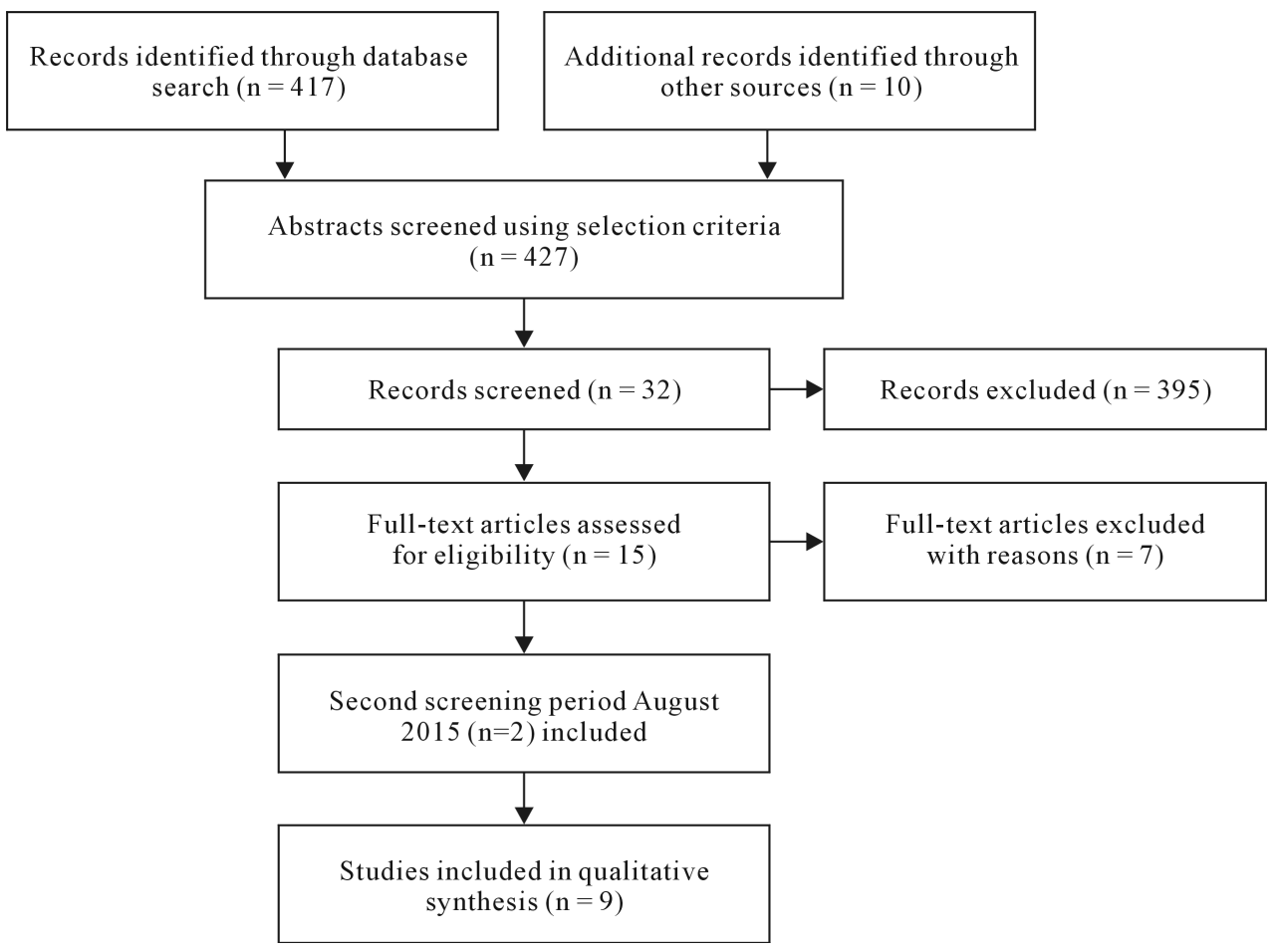

Figure 1. Flowchart of search outcomes and the included studies (PRISMA) [21].

\subsection{Characteristics of the Included Articles}

Most of the papers described AEs and near-misses from the perspective of healthcare professionals [23] [24], [26]-[30]. A majority of the reported AEs and near-misses were related to systemic failure, medication and drug errors [23]-[25] [28] and communication breakdowns, error in reporting and under-reporting [30], case management problems [28], failure to diagnose or act appropriately [28], lack of prioritization of safety [30] and infections [24] [25], leading to maternal death and severe morbidity for the child [25] [28]-[30] (Table 1).

The selected studies were conducted in four countries; Australia [22], the United Kingdom [23] [26] [28] [30] the United States of America [24] [25] [27] and the Netherlands [29]. They employed different designs such as survey, qualitative, experimental and a series of case reports. The most common weaknesses in the quantitative study design were related to sampling, design and low response rate [22] [23] [28]. One of the strengths of this group of studies was the use of theory [22], and/or evidence-based knowledge [25] [26] [29] to guide the research and recommendations about how to support and improve PS [22]-[26] [28]-[30].

The results are presented based on the themes that emerged: The types of $A E$ and near-misses and their consequences, Strategies to support and improve PS and the Domains related to the WHO's Patient Safety Competence Outcomes. The findings of the first theme were grouped into categories: Healthcare professionals' perspectives on ethical conflicts, attributing blame and responsibility, and Patients' perspectives on lack of trust and involvement, as well as medication errors. The second theme Strategies to support interventions to improve patient safety was based on two sub-themes: Communicating effectively and Gaining competence by learning from adverse events, while the third theme was Domains related to the WHO Patient Safety Competence Outcomes.

The relationship pattern between the types of AEs, near-misses and their consequences, as well as the strategies to support PS and the domains related to the WHO's model are presented in Table 2. Finally, the relationship between AEs and near misses, strategies to support and improve PS and the WHO Patient Safety Model was interpreted.

\subsection{Types of AE, Near-Miss and Their Consequences}

Using thematic analysis, a total of twelve types of $\mathrm{AE}$ and near-miss emerged, which were categorized into two sub-themes, 1) the healthcare professionals' perspectives and 2) the patients' perspectives. 
Table 1. Summary of the included articles on adverse events (AEs) and near-misses in the context of patient safety (PS).

\begin{tabular}{|c|c|c|c|c|c|c|}
\hline $\begin{array}{l}\text { Author } \\
\text { country }\end{array}$ & $\begin{array}{c}\text { Aim and } \\
\text { Research question }\end{array}$ & $\begin{array}{l}\text { Subjects and } \\
\text { study setting }\end{array}$ & Method/design & Data analysis & Types of AEs and near-misses & Support intervention \\
\hline $\begin{array}{c}\text { Allen } \text { et al. } \\
\text { [22] } \\
\text { Australia }\end{array}$ & $\begin{array}{l}\text { To report a case } \\
\text { study examining } \\
\text { the safety culture }\end{array}$ & $\begin{array}{l}\text { Midwives, obstetric } \\
\text { registrars, medical } \\
\text { officers and obstetric } \\
\text { staff specialists. } \\
\mathrm{n}=210 \mathrm{n}=15\end{array}$ & $\begin{array}{l}\text { Descriptive } \\
\text { case study; } \\
\text { Questionnaires; } \\
\text { Semi-structured } \\
\text { interviews }\end{array}$ & $\begin{array}{c}\text { Descriptive } \\
\text { Statistics; } \\
\text { Mean score } \\
\text { template analysis }\end{array}$ & $\begin{array}{l}\text { Incident reports were } \\
\text { highlighted; } \\
\text { No specific types of AEs } \\
\text { were reported. }\end{array}$ & $\begin{array}{l}\text { Infrastructure and capacity to } \\
\text { support management activity; } \\
\text { Improved leadership to } \\
\text { strengthen the safety culture }\end{array}$ \\
\hline $\begin{array}{l}\text { Lawton } \\
\text { et al. [23] } \\
\text { UK }\end{array}$ & $\begin{array}{l}\text { To explore the assessment } \\
\text { of PS, the outcome of } \\
\text { care (harm or not) and } \\
\text { relationship (good or bad) } \\
\text { with the care provider }\end{array}$ & $\begin{array}{l}\mathrm{N}=98 \text { mothers, who } \\
\text { had between one and } \\
\text { five children }\end{array}$ & $\begin{array}{l}\text { Four } \\
\text { hypothetical } \\
\text { vignettes in a } \\
\text { questionnaire, }\end{array}$ & Multivariate analysis & $\begin{array}{l}\text { Referral for big baby; } \\
\text { VE after ruptured membrane; } \\
\text { Discussion of the prescription } \\
\text { of iron tablets and pethidine }\end{array}$ & $\begin{array}{c}\text { Theory and policy } \\
\text { development; } \\
\text { Improving relationships between } \\
\text { patients and professionals }\end{array}$ \\
\hline $\begin{array}{l}\text { Gephart } \\
\text { et al. [24] } \\
\text { USA }\end{array}$ & $\begin{array}{l}\text { To describe failure to } \\
\text { rescue in neonatal } \\
\text { intensive care and outline } \\
\text { the nursing and system } \\
\text { rescue actions that can } \\
\text { be taken to rescue }\end{array}$ & $\begin{array}{c}\text { Nurses; } \\
\text { Respiratory therapist; } \\
\text { Transport team; } \\
\text { Neonatologists; } \\
\text { Pharmacist; } \\
\text { Auxiliary staff }\end{array}$ & $\begin{array}{l}3 \text { cases of } \\
\text { failure }\end{array}$ & $\begin{array}{l}\text { Interpretation of the } \\
\text { rescue process; Activating } \\
\text { a team response; } \\
\text { Surveillance; Timely } \\
\text { recognition of } \\
\text { complications and } \\
\text { Taking action }\end{array}$ & $\begin{array}{l}\text { Premature labour, not } \\
\text { adequately managed and } \\
\text { prenatal steroids not given; } \\
\text { Infant delivered to mother with } \\
\text { positive group B streptococcus } \\
\text { not treated in labour; } \\
\text { Preterm infant who developed } \\
\text { necrotizing enterocolitis }\end{array}$ & $\begin{array}{l}\text { Team training, high-risk clinical } \\
\text { drills, use of professional } \\
\text { guidelines, standardized } \\
\text { documentation; } \\
\text { The CUS technique "I am } \\
\text { Concerned, I am Uncomfortable } \\
\text { This is a Safety issue" }\end{array}$ \\
\hline $\begin{array}{l}\text { Kfuri et al. } \\
\text { [25] USA }\end{array}$ & $\begin{array}{l}\text { To discuss prescription and } \\
\text { use of medication during } \\
\text { pregnancy and analysis } \\
\text { of medication errors } \\
\text { in obstetrics }\end{array}$ & $\begin{array}{l}\text { Labour/delivery; } \\
\text { Maternity ward; } \\
\text { Obstetric recovery } \\
\text { room }\end{array}$ & $\begin{array}{l}\text { Series of case } \\
\text { reports on } \\
\text { medication } \\
\text { errors in } \\
\text { obstetrics } \\
\mathrm{N}=4583\end{array}$ & $\begin{array}{l}\text { Analysis of the } \\
\text { MEDMARX Medication } \\
\text { error reports of omission, } \\
\text { wrong time, improper dose, } \\
\text { unauthorized/wrong drug, } \\
\text { extra dose, drug prepared } \\
\text { incorrectly, wrong } \\
\text { administration technique, } \\
\text { wrong patient, wrong } \\
\text { dosage form }\end{array}$ & $\begin{array}{c}\text { Intrapartum infection; } \\
\text { Lower analgesic efficiency; } \\
\text { Severe depression; } \\
\text { Bleeding; Hepatitis; Nausea; } \\
\text { Maternal death; } \\
\text { Malaise; } \\
\text { Arrest of labour; } \\
\text { Multiple-drug } \\
\text { resistant MRSA }\end{array}$ & $\begin{array}{c}\text { Pharmacy-led medication } \\
\text { safety team; } \\
\text { On-line reporting; } \\
\text { Computerised physician order } \\
\text { entry/Clinical decision support; } \\
\text { Medication related; } \\
\text { Barcode-enabled point-of-care; } \\
\text { Pharmacy barcode; } \\
\text { E-prescribing barcode }\end{array}$ \\
\hline $\begin{array}{l}\text { Scholefield } \\
\text { [26] UK }\end{array}$ & $\begin{array}{l}\text { To report structures } \\
\text { and processes for } \\
\text { improving quality } \\
\text { of care and patient safety }\end{array}$ & $\begin{array}{l}\text { Staff and patients } \\
\text { at women's and } \\
\text { neonatal services }\end{array}$ & Implementation & $\begin{array}{l}\text { Debriefing with } \\
\text { patients and after } \\
\text { complications }\end{array}$ & $\begin{array}{l}\text { Managing haemorrhage, } \\
\text { delay in providing blood } \\
\text { transfusion, poor use of } \\
\text { protocols, or failure to call } \\
\text { senior staff; } \\
\text { Handover was recognized } \\
\text { as an area of risk; } \\
\text { Delay in transfer to } \\
\text { other units }\end{array}$ & $\begin{array}{l}\text { Team briefings; Regular meetings } \\
\text { and “walk-about”; Appropriate } \\
\text { and learning multidisciplinary } \\
\text { learning; Supporting as opposed } \\
\text { to blaming staff in difficult } \\
\text { circumstances; Involving and } \\
\text { communicating with and } \\
\text { involving patients in their own } \\
\text { care and treatment; Mapping } \\
\text { and analysing the events }\end{array}$ \\
\hline $\begin{array}{l}\text { Simpson } \\
\text { et al. [27] } \\
\text { USA }\end{array}$ & $\begin{array}{l}\text { To describe } \\
\text { communication between } \\
\text { nurses and physicians } \\
\text { during labour within } \\
\text { the context of the } \\
\text { nurse-managed } \\
\text { labour model }\end{array}$ & $\begin{array}{l}\mathrm{n}=54 \text { nurses and } \\
\mathrm{n}=38 \text { obstetricians; } \\
\text { Labour and birth units } \\
\text { in community hospitals }\end{array}$ & $\begin{array}{l}\text { Focus groups } \\
\text { and in-depth } \\
\text { interviews }\end{array}$ & $\begin{array}{l}\text { Inductive coding } \\
\text { methods }\end{array}$ & $\begin{array}{l}\text { Discussion of oxytocin } \\
\text { rate to maintain adequate } \\
\text { contractions, time for } \\
\text { admission and epidural } \\
\text { anaesthesia }\end{array}$ & $\begin{array}{l}\text { PS is enhanced when the } \\
\text { hierarchy is flattened so that all } \\
\text { team members are encouraged } \\
\text { and feel obliged to voice } \\
\text { concerns about situations with } \\
\text { a potential risk of patient harm; } \\
\text { Interdisciplinary teamwork }\end{array}$ \\
\hline $\begin{array}{l}\text { Symon } \\
\text { et al. [28] } \\
\text { UK }\end{array}$ & $\begin{array}{l}\text { To investigate midwives' } \\
\text { understanding and } \\
\text { recollections of } \\
\text { clinical near misses }\end{array}$ & $\begin{array}{l}\text { Midwives in four obstetric } \\
\text { maternity units } \mathrm{n}=34 ; \\
\text { Group interviews with } \\
\text { midwives } \mathrm{n}=26 \text {; } \\
\text { Antenatal clinic, home birth, } \\
\text { labour ward, obstetric } \\
\text { theatre, postnatal unit and } \\
\text { postnatal community care }\end{array}$ & $\begin{array}{l}\text { A postal survey; } \\
\text { Questionnaire } \\
\text { Interviews }\end{array}$ & $\begin{array}{l}\text { Descriptive statistics } \\
\text { Open-text analysis } \\
\text { and interpretation } \\
\text { of midwives' } \\
\text { understanding of and } \\
\text { response to near misses }\end{array}$ & $\begin{array}{l}\text { Case management problems; } \\
\text { Communication failure; } \\
\text { Equipment failure; } \\
\text { Failure to diagnose/act } \\
\text { appropriately; } \\
\text { Syntocin infusion problems } \\
\text { Drug errors }\end{array}$ & $\begin{array}{l}\text { Helping to prevent mistakes } \\
\text { by learning from past errors; } \\
\text { Continuity of care; } \\
\text { Clinical supervision; } \\
\text { The need for openness in } \\
\text { clinical practice }\end{array}$ \\
\hline $\begin{array}{c}\text { Martijn } \\
\text { et al. [29] } \\
\text { Netherlands }\end{array}$ & $\begin{array}{l}\text { To perform a } \\
\text { structural analysis } \\
\text { of determinants of } \\
\text { the risk of critical } \\
\text { incidents in care }\end{array}$ & $\begin{array}{l}\mathrm{N}=71 \text { critical incidents } \\
\text { in primary midwifery } \\
\text { care and subsequent } \\
\text { in-patient hospital care }\end{array}$ & $\begin{array}{l}\text { Instrument } \\
\text { to identify } \\
\text { determinants } \\
\text { of adverse } \\
\text { outcomes and } \\
\text { near misses }\end{array}$ & Case-by-case analysis & $\begin{array}{l}\text { Maternal death; } \\
\text { Severe maternal morbidity; } \\
\text { Perinatal death; } \\
\text { Severe morbidity of the child }\end{array}$ & $\begin{array}{l}\text { Diagnostic procedures and } \\
\text { medical treatment; } \\
\text { Organization of emergency care; } \\
\text { Task description and delineation; } \\
\text { Record keeping; } \\
\text { Communication between care } \\
\text { providers; Structural training } \\
\text { Written protocols }\end{array}$ \\
\hline $\begin{array}{l}\text { Currie \& } \\
\text { Richens } \\
\text { [30] UK }\end{array}$ & $\begin{array}{l}\text { To describe midwifery } \\
\text { staff's perception of } \\
\text { safety culture and make } \\
\text { recommendations for a } \\
\text { positive safety culture }\end{array}$ & $\begin{array}{c}\mathrm{N}=5 \text { senior midwifery } \\
\text { managers, } \mathrm{n}=6 \text { community } \\
\text { midwives, } \mathrm{n}=17 \text { midwifery } \\
\text { students and } \mathrm{n}=5 \text { midwifery } \\
\text { support staff; } \\
\text { Obstetric hospital }\end{array}$ & Focus groups & $\begin{array}{l}\text { Qualitative analysis } \\
\text { included descriptions of } \\
\text { group context, group } \\
\text { interaction, use of } \\
\text { humour and any areas } \\
\text { of disagreement }\end{array}$ & $\begin{array}{c}\text { Error reporting and } \\
\text { under-reporting; } \\
\text { Client expectation of the service; } \\
\text { Decision-making and } \\
\text { staffing; } \\
\text { Communication; } \\
\text { Prioritization of safety; } \\
\text { Staff safety }\end{array}$ & $\begin{array}{l}\text { All staff should be given } \\
\text { authority to report accidents, } \\
\text { incidents, near-misses and } \\
\text { safety concerns; } \\
\text { Feedback and dissemination } \\
\text { mechanisms need to be improved } \\
\text { to guarantee learning outcomes }\end{array}$ \\
\hline
\end{tabular}

VE = Vaginal Examination, MRSA = Methicillin Resistant Staphylococcus Aureus. 
Table 2. Synthesis of the characteristics of the types of AEs, near-misses and their consequences, strategies to promote PS, and their relationship to the WHO's Patient Safety Model [17].

\begin{tabular}{|c|c|c|}
\hline $\begin{array}{l}\text { Types of AEs, near-misses and their } \\
\text { consequences }\end{array}$ & $\begin{array}{l}\text { Strategies to promote interventions to } \\
\text { improve PS }\end{array}$ & $\begin{array}{l}\text { Domains related to the WHO's } \\
\text { Patient Safety Competence Outcomes }\end{array}$ \\
\hline $\begin{array}{l}\text { HCPs: Psychosocial and physical attribution of } \\
\text { blame and responsibility [23] [24]; } \\
\text { Managing risks [26]; } \\
\text { Near-misses and AEs are judged in terms of } \\
\text { events and on how others react to them [28]; } \\
\text { Failure to recognize and respond to unexpected } \\
\text { changes in a woman's condition during labour [30]; } \\
\text { Failure to learn lessons [30] }\end{array}$ & $\begin{array}{l}\text { Safety culture [22] [26] [30] and policy } \\
\text { development [23]; } \\
\text { Leading and supporting staff [26]; } \\
\text { Promoting reporting and being open when } \\
\text { things go wrong [26] [28] [30]; } \\
\text { Learning and sharing safety lessons [26] } \\
\text { [28] [30] }\end{array}$ & $\begin{array}{l}\text { Contribute to patient safety culture } \\
\text { by increased reporting of AEs and } \\
\text { near-misses }\end{array}$ \\
\hline $\begin{array}{l}\text { HCPs: Inadequate communication between } \\
\text { HCP's in the healthcare system (community and } \\
\text { in-hospital) [24] [27] and with the patient [29] }\end{array}$ & $\begin{array}{l}\text { Feedback and acknowledgement [30]; } \\
\text { Team training, high-risk clinical drills, } \\
\text { use of professional guidelines and standard } \\
\text { documentation [24] [28]-[30]; } \\
\text { Task description and delineation [29] }\end{array}$ & $\begin{array}{l}\text { Communicate effectively; } \\
\text { Teamwork and collaboration }\end{array}$ \\
\hline $\begin{array}{l}\text { HCPs: Ethical conflicts due to } \\
\text { misunderstanding [30] }\end{array}$ & $\begin{array}{l}\text { Safety climate, the possibility to talk about } \\
\text { failure [24]; } \\
\text { Helping to prevent mistakes [28]; } \\
\text { Prioritization of safety [30] }\end{array}$ & $\begin{array}{l}\text { Identify failure modes; } \\
\text { Identify maternal near-miss }\end{array}$ \\
\hline $\begin{array}{l}\text { HCPs: Inadequate infrastructure [22]; } \\
\text { Referral procedures, risk assessment by } \\
\text { telephone triage and technical procedures [29] }\end{array}$ & $\begin{array}{l}\text { Support incident management activities and } \\
\text { leadership capacity [22] }\end{array}$ & $\begin{array}{l}\text { Optimize environmental resources } \\
\text { to ensure PS }\end{array}$ \\
\hline $\begin{array}{l}\text { PH: Loss of trust and responsibility for their } \\
\text { own safety [23] [24] }\end{array}$ & $\begin{array}{l}\text { Involving and communicating with patients } \\
\text { and the public [26]; } \\
\text { Involving patients in their own care and } \\
\text { treatment [26]; } \\
\quad \text { Use of clinical decision support [25] [30] }\end{array}$ & Optimize patient-centred care \\
\hline $\begin{array}{l}\text { PH: Wrong obstetric medication resulting in } \\
\text { harmful errors [25]; } \\
\text { Medication procedures [29] }\end{array}$ & $\begin{array}{l}\text { Medication administration that enables } \\
\text { interdisciplinary quality improvement [25] } \\
\text { [28] }\end{array}$ & $\begin{array}{l}\text { Manage safety risks } \\
\text { Leadership }\end{array}$ \\
\hline PH: Perinatal cases of patients’ complaints [29] & Clinical management [29] & Manage safety risks \\
\hline
\end{tabular}

AE = Adverse Events; PS = Patient Safety; WHO = World Health Organization; HCPs = Healthcare Professionals; PH = Patient Harm .

\subsubsection{Healthcare Professionals' Perspectives on Ethical Conflicts, Attributing Blame and Responsibility}

This theme was associated with the relationship between healthcare professionals. Ethical conflicts due to inadequate communication and misunderstanding were reported. Their attitudes and values in terms of attributing blame, responsibility and managing risks, as well as how other reacted to them were described. In addition, failure to recognize and respond to unexpected changes during labour was reported. A lack of clinical decision support and difficulty implementing and prioritizing safety strategies were also mentioned.

\subsubsection{Patients' Perspectives on Lack of Trust and Involvement, as Well as Medication Errors} This theme includes patients' experiences of lack of trust and lack of involvement in their own safety care. Two of the studies reported wrong medication resulting in harmful errors.

\subsection{Strategies to Support Interventions to Improve PS}

With the exception of one, all studies mentioned supportive interventions to improve PS. Safety culture and climate were related to team training, high-risk clinical drills, use of professional guidelines, task description and reporting. The safety culture included a climate of openness when things went wrong, learning and sharing safety lessons as well as the importance of feedback and acknowledgement. Supportive management activities and leadership capacity were also highlighted. 


\subsubsection{Communicating Effectively}

Aspects reflecting individual, team and organizational productivity were reported. Communication between healthcare professionals was described as inadequate and a greater awareness of AEs and near-misses was deemed necessary. Communication with the patients and their family members was considered lacking. Patients' expectations of being involved and assuming responsibility for their own safety were not fulfilled. Wrong obstetric medication resulting in harmful errors that could have been due to a misunderstanding was reported. Consequently, strategies for involving and communicating with patients and their family members were considered essential.

\subsubsection{Gaining Competence by Learning from Adverse Events}

This theme is related to reports of the need for team training, high-risk clinical drills, help to understand and use guidelines and standard documents, in addition to task description. It also reveals the need for leadership and incident support management activities. Learning from AEs and near-misses was described as a resource and a means of preventing mistakes.

\subsection{The Relationship between AEs, Near-Misses, Strategies and the WHO's Patient Safety Model}

Table 2 describes the relationship between AEs, near-misses, strategies to promote PS, and the WHO Patient Safety Model [17]. The core components related to PS competence are the capacity to contribute to the patient safety culture by increased reporting of AEs and near-misses, as well as optimizing environmental resources to ensure PS. From the perspective of healthcare professionals, PS involves their ability to communicate effectively and identify failure modes and near-misses in a culture characterized by teamwork and collaboration. From the patient perspective, PS concerns healthcare professionals' capacity building competence, ability to optimize patient-centred care and manage safety risks.

\section{Discussion}

This study uniquely contributes to the literature on PS, AEs and near-misses in obstetric care in at least four ways: 1) We provide an overview of the recent literature on the subject per se, the types of healthcare AEs in the context of PS, the prevention and support interventions that were implemented, as well as perspectives on the WHOPS competence outcomes. 2) The present literature review helps to elucidate the impact of AEs and near-misses. 3) Twelve types of AE and near-miss were identified and categorized from two perspectives, thus providing a deeper understanding of the phenomenon. Based on the existing literature, the healthcare professionals' perspectives included ethical conflicts, attributing blame and responsibility, communicating effectively and gaining competence by learning from adverse events, while the patients' perspective highlighted strategies for managing safety risks and preventing harm. 4) The meaning of patients' experiences of responsibility for their own safety, lack of trust and medication errors was also included.

\subsection{Healthcare Professionals' Perceptions of Ethical Conflicts, Attributing Blame and Responsibility}

Aspects of the quality and safety culture are described in several ways, including ethical conflicts. Interventions for improving PS, healthcare systems, processes and outcomes are suggested on organisational-, group- and individual levels. Challenges on the individual level remain, as personal attributes seem to play a major role in the commitment to learn from the consequences of AEs and near-misses. Evidence of individuals' attitudes to reporting, analysing and learning from AEs and near-misses is less frequently described. This is specifically concerns the ability to recognize AEs and near-misses, feeling obliged to voice concerns about situations with a potential risk of patient harm [27] and whether or not to report the event [30]. This finding is in line with Barach and Small [31], who focused on barriers and incentives to reporting near-misses. On the individual level a barrier can be lack of trust and fear of reprisals, leading to reluctance to report near-misses. Trust is fundamental to interpersonal relationships and involves an expectation of being seen, heard and treated with respect [32]. Being in need of support through communication with another person can be considered self-disclosure, which makes an individual vulnerable by exposing her/him to the risk of being ignored [32]. The other person has the power to decide whether to accommodate or ignore [32]. Trust is a prerequisite for communicating complex issues. 
Lack of trust between healthcare professionals creates mistrust, which can be a barrier to open communication [27]. Barach and Small [31] stated that an example of a common conflict in near-miss reporting systems is sacrificing accountability for information, i.e., negotiating moral hazards when choosing between the good of society and the needs of individuals.

The WHO Patient Safety Model [17] highlights the importance of identifying failure modes in PS. Strategies are required to improve PS within large organizations, therefore reflection and critical incident analysis models are necessary to assist healthcare professionals to achieve predictable learning outcomes. Symon et al. [28] underline the need for openness in clinical practice, as well as clinical support such as supervision. Clinical supervision allows time to reflect on and learn from experiences and has been reported to lead to improved competence development in form of increased interpersonal, professional and communication skills [33] [34]. From an ethical perspective Berggren and Severinsson [35] explored the decision-making style of nurse supervisors from an ethical perspective by focusing on their priorities and interventions in the supervision process. The interventions involved sharing knowledge and values with the supervisees, in addition to recognizing them as nurses and human beings. Furthermore, the core components of supervision as demonstrated in supervision sessions are: guilt, reconciliation, integrity, responsibility, conscience and challenge. When describing supervisors' ethical styles Berggren et al. [35] identified three core themes: "Is it safe?”; "Is it right?”; and "Is it kind?”, when describing supervisors' ethical styles. The first theme covered the supervisors' rules, codes and values that guide their supervisory actions, and comprised two subthemes: empowerment and integrity. The second theme 'Is it right?' described the supervisors' responsibility and advocacy as well as the ethical dilemmas experienced in the supervisory process. Finally, the theme "Is it kind?" included the supervisors' relationships with patients, professionals and supervisees. A study revealed that midwives' supervisory styles were related to their ability to create a trusting and caring relationship, demonstrate problem-solving capacity, and exhibit willingness, preparedness and courage to support the women [36] [37]. The midwives' leadership role was described as involving a crucial set of professional management skills and techniques. Thus, attending supervision may positively influence the PS culture when the healthcare professionals reflect on, respond to and disclose AEs.

\subsection{Communicating Effectively and Gaining Competence by Learning from Adverse Events}

Communication is a core aspect of PS culture. Poor communication between healthcare professionals' is a well-known patient safety risk [29]. According to Simpson et al. [27], healthcare professionals' interactions with each other and patients should be respectful, creating a situation characterized by kindness and caring.

PS culture should be based on trust, open communication and effective teamwork [27]. How persons should be treated is a complex question that in part depends on ideas about humanity, norms, values and what is good for other individuals [38]. Meeting, listening, being open to different possibilities, and sharing lived experiences help create an enabling environment for learning [39]. Instead of direct communication between colleagues leading to a care plan developed through the wisdom and experiences of knowledgeable professionals, healthcare professionals sometimes choose to act on the basis of what they think is in the patient's best interests [27]. Interdisciplinary communication between healthcare professionals has sometimes proved to be minimal [27]. Furthermore, communication and teamwork could be improved to promote patient safety during labour and birth [27]. In the aforementioned study it was found that the first focus of improvement should be internal communication by means of a standardized handover tool [29]. This is in line with Simpson et al. [27], who emphasized that future research should prioritise identification of interventions for improving teamwork and PS. Standardized tools and expected behaviours are known to be effective strategies for enhancing teamwork and reducing the risk of patient harm.

Thus, improved interdisciplinary communication and incident reporting are necessary to maintain PS. The key benefit of improved PS is identification and appropriate management of risks ([40], p. 44). Other benefits are staff involvement in risk management processes, professional accountability and responsibility [40]. While feedback to those who report AEs and near-misses is also important, it often does not occur as it is dependent on the PS culture.

\subsection{Patients' Perspective on Lack of Trust and Involvement, as Well as Medication Errors}

It was revealed that patients experienced lack of trust and involvement in their own safety care, which raises 
questions about midwifery and medical care models. The approaches resulting from midwifery and medical perspectives can be seen as complementary and an outcome of teamwork between midwives and physicians [41]. Midwifery focuses on the normalcy of pregnancy and birth, which are seen as a natural process and midwives are experts in supporting and enhancing labour and delivery. The medical model concentrates on the pathology of pregnancy and birth. In the present review the main focus was on AEs and near-misses in obstetric care, i.e., labour and birth complications. The benefits of midwifery models of care are several. Continuity of Care (COC) has been defined as starting in early pregnancy and continuing through the pregnancy, labour and birth until the end of the postnatal period [42]. The key principles are: 1) ability to develop a meaningful relationship with the women; 2) occupational autonomy and flexibility so that midwives are in control of their own work, enabling them to organise and prioritise; and 3) support at work that includes regular meetings with colleagues to reflect on practice, share ideas and information, as well as knowing when certain colleagues may need more support due to personal or professional circumstances [43]. COC is an important factor for enhancing quality of care, trust and confidence, as well as overall satisfaction [44]. Women who had a midwife-led care model were less likely to experience hospitalisation (risk ratio (RR) 0.90 , 95\% confidence interval (CI) 0.81 to 0.99 ), the use of local analgesia (RR $0.81,95 \%$ CI 0.73 to 0.91 ), episiotomy (RR 0.82, 95\% CI 0.77 to 0.88 ), instrumental delivery (RR 0.86 , $95 \%$ CI 0.78 to 0.96 ) and were likely to experience no intrapartum analgesia/anaesthesia (RR 1.16, 95\% CI 1.05 to 1.29), spontaneous vaginal birth (RR 1.04, 95\% CI 1.02 to 1.06), to feel in control during labour and childbirth (RR 1.74, 95\% CI 1.32 to 2.30), be attended during the birth by a familiar midwife (RR 7.84, 95\% CI 4.15-14.81) and initiate breastfeeding (RR 1.35, 95\% CI 1.03 to 1.76 [45]. Homer et al. [46] tested whether a new community-based model COC provided by midwives and obstetricians improved maternal clinical outcomes, in particular by reducing the caesarean section rate. The findings demonstrated a significant difference in the caesarean rate between the community group and the control group. COC has been shown to reduce interventions in labour, particularly augmentation of labour, analgesic use and electronic foetal monitoring [47].

Communication and relationships should be fostered in healthcare to maintain PS. This is in line with McCormack and McCance [48], who emphasize that relationships are built on understanding and sharing collective knowledge. The theory of person-centredness is important for optimizing a patient-centred care model [17], which is based on a humanistic approach where all individuals are seen as unique, worthy, competent and equal. According to the theory of person-centredness, a patient should be invited to take part in a dialogue and offered choices through a therapeutic relationship in which she/he is empowered to become involved in decisions [48].

The person-centred approach means that responsibility, knowledge and initiative are shared between the professional and the patient [48]. Entwistle and Watt [38] state that in quick thoughts or casual conversations, healthcare professionals' tend to equate person-centred care with doing what patients say they like, which means that the deep value base, intrinsic worth and complexity of the concept can be lost. For example, when a patient is harmed by treatment, the natural wish of both the patient and healthcare professionals can be to distance themselves from one another. In such a situation the healthcare professionals are responsible for ensuring continuity of care and maintaining the therapeutic relationship.

Patient and their families need support after AEs [49]. An unreflective emphasis on preferences can detach the idea of person-centred care from what is ethically significant, especially when preferences are not well informed, stable, strong or good, or do not relate to issues of importance. In some cases this can demand more of healthcare professionals than existing interpretations of person-centred care because it also requires personal capabilities [38]. Therefore, in order to manage safety risks it is important to include patients' expectations of being a decision-maker. According to Ofstad [50], a person may be free to make decisions based on her/his own experiences. However, many factors influence the decision-maker, i.e., biological factors, environmental factors, interests and affects, feelings and desires, purpose of the decision-making, the willingness to make decisions, as well as the individual's value and norm system. Moore et al. ([51], p. 278) highlight the women's active involvement in decision making. They developed a patient-centred implementation model in order to ensure the safety of the baby and trust in clinicians. Important concepts in the model are awareness, knowledge, intention, and expectations related to the safety of the baby. The concepts related to trust in midwives and physicians are attitudes, intentions, and expectations of involvement in decision-making. Shared decision-making implies that patients should be informed about the essential role they play in decisions and receive the support they need to express their values and be able to ask questions to successfully address the components of quality and safety [52]. Moore et al. [51] and Moore et al. [53] studied shared decision-making in relation to induction of labour. 
They found that women tend to favour the care they are offered and avoid demanding recommendations from their clinician. Informed, shared decision-making should be encouraged as a first step to address the risks associated with the induction of labour. This is in accordance with Scholefield [55], who argued that risk management is the key to improving the safety of care. It is necessary to understand the theory of human error and the system, rather than a person-centred approach to dealing with AEs. Thus, risk management has many components including learning and education from adverse incidents. A Japanese study showed that the time devoted to patient safety education is four hours or less [56].

\subsection{Limitations}

This review was limited by the fact that it only included nine published articles. In the review we used the PRISMA checklist of items to report and analyse the quality of the articles [21]. The terminology in PRISMA was developed from the definitions used by the Cochrane collaboration [54], a clearly formulated questionnaire that employs systematic and explicit methods to identify, select, and critically appraise relevant research. A limitation is that some checklist items were not used because they were not relevant to the review questions addressed. For example, we did not describe all information about the methodological quality of the studies, such as population, sampling methods, response rate, data collection procedures, measurements, reliability and validity or the statistical method. We focused on the integration of the findings in order to answer the review questions.

\section{Conclusions and Future Research}

The key question is whether or not healthcare professionals dare to report AEs or not. It is probable that they are influenced by the PS culture. It is very serious if incident reports are expected to lead to improved PS but routines are not changed. The need for further research was clearly indicated by the fact that our inclusion and exclusion criteria limited the number of studies in the review. Future research should include assessment of patients' experiences of the person-centred care model such as perceived lack of responsibility in the context of PS. To date, there have been relatively few studies of patients' role in their own safety. In addition, future studies should elaborate on the definition of PS and medical safety in order to identify similarities and differences.

\section{Acknowledgements}

This work is supported by The Japan Society for Promotion of Science (ID No. S15190) and awards to Professor Elisabeth Severinsson for her work at the Department of Midwifery and Women's Health at the University of Tokyo. The authors would like to thank Monique Federsel for reviewing the English language and specialized librarian at the Buskerud \& Vestfold University College, for her valuable help with the electronic search for articles.

\section{Competing Interests}

The authors declare that there are no conflicts of interest.

\section{Contributors}

E.S. planned the study, as well as designing and conducting the systematic review. All authors contributed to the data analysis. E.S. coordinated the research and supervised the analysis. All authors contributed intellectually to the writing of the manuscript. All authors read and approved the final manuscript.

\section{References}

[1] Lindsay, P. (2014) Maternity Support Workers and Safety in Maternity Care in England. The Practising Midwife, 17, 20-22.

[2] Sammer, C., Lykens, K., Singh, K., Mains, D. and Lackan, N. (2012) What Is Patient Safety Culture? A Review of the Literature. Journal of Nursing Scholarship, 42, 156-165. http://dx.doi.org/10.1111/j.1547-5069.2009.01330.x

[3] Kohn, L., Corrigan, J. and Donaldson, M., Eds. (2000) To Err Is Human: Building a Safer Health System. Committee on Quality of Healthcare in America, Institute of Medicine, National Academy Press, Washington DC. 
[4] Taylor, L.S., Dy, S., Foy, R., Hempel, S., McDonald, K.M., Ovretveit, J., Pronovost, P.J., Rubenstein, L.V., Wachter, R.M. and Shekelle, P.G. (2012) What Context Features Might Be Important Determinants of the Effectiveness of Patient Safety Practice Interventions? BMJ QualitySafety, 20, 611-617. http://dx.doi.org/10.1136/bmjqs.2010.049379

[5] Milligan, F. and Dennis, S. (2005) Building a Safety Culture. Nursing Standard, 23, 48-52. http://dx.doi.org/10.7748/ns2005.11.20.11.48.c4011

[6] Hasley, S.K. (2011) Decision Support and Patient Safety: The Time Has Come. American Journal of Obstetrics and Gynecology, 204, 461-465. http://dx.doi.org/10.1016/j.ajog.2010.10.901

[7] Madden, I. and Milligan, F. (2004) Enhancing Patient Safety and Reporting Near Misses. British Journal of Midwifery, 12, 643-647. http://dx.doi.org/10.12968/bjom.2004.12.10.16105

[8] Department of Health (2001) Building a Safer NHS for Patients: Implementation an Organisation with a Memory. The Stationary Office, London. www.doh.gov.uk/buildsafenhs

[9] Say, L., Souza, J. P., Pattinson, R.C., et al. (2009) Maternal Near Miss-Towards a Standard Tool for Monitoring Quality of Maternal Health Care. Best Practice \& Research Clinical Obstetrics and Gynaecology, 23, 287-296. http://dx.doi.org/10.1016/j.bpobgyn.2009.01.007

[10] Khan, S.K., Wojdyla, D., Say, L., Gülmezoglu, M.A. and Van Look, P. (2006) WHO Analysis of Causes of Maternal Death: A Systematic Review. The Lancet, 367, 1066-1074. http://dx.doi.org/10.1016/S0140-6736(06)68397-9

[11] World Health Organization (2014) Safe Childbirth Checklist Collaboration: Improving the Health of Mothers and Neonates. http://www.who.int/patientsafety/implementation/checklists/childbirth_collaboration_engaging/en/

[12] Renfrew, M.J., McFadden, A., Bastos, M.H., Campell, J., Channon, A.A., Cheung, F.N., Delage Silva, D.R.A., Downe, S., Kennedy, H.P., Malata, A., McCormick, F., Wick, L. and Declercq, E. (2014) Midwifery and Quality Care: Findings from a New Evidence-Informed Framework for Maternal and Newborn Care. The Lancet, 384, 1129-1145. http://dx.doi.org/10.1016/S0140-6736(14)60789-3

[13] Ten Hoope-Bender, P., de Bernis, L., Campell, J., Downe, S., Fauveau ,V., Fogstad, H., Homer, C., Kennedy, P.H., Matthews, Z., McFadden, A., Renfrew, M.J. and Van Lerberghe, W. (2014) Improvement of Maternal and Newborn Health through Midwifery. The Lancet, 384, 1226-1235. http://dx.doi.org/10.1016/S0140-6736(14)60930-2

[14] Vincent, C. (2003) Understanding and Responding to Adverse Events. The New England Journal of Medicine, 348, 1051-1056. http://dx.doi.org/10.1056/NEJMhpr020760

[15] Régo, P., Lyon, P. and Watson, M. (2011) The Impact of Maternity Crisis Resource Management Training. British Journal of Midwifery, 19, 315-323. http://dx.doi.org/10.12968/bjom.2011.19.5.315

[16] World Health Organization (2008) International Classification for Patient Safety for Use in Field Testing in 2007-2008. Geneva.

[17] World Health Organization (WHO) (2009) Download the WHO Patient Safety Curriculum Guide for Medical Schools. http://www.who.int/patientsafety/education/curriculum/download/en/index.html

[18] World Health Organization (WHO) (2011) Public Health Surveillance. http://www.who.int/topics/public_health_surveillance/en/

[19] World Health Organization (WHO) (2011) The WHO Near-Miss Approach. http://www.who.int/reproductivehealth/topics/maternal_perinatal/nmconcept/en/

[20] Peters, D., Tran, N.T. and Adam, T. (2013) Implementation Research: What It Is and How to Do It. BMJ, 347, f6753.

[21] Moher, D., Liberati, A., Tetzlaff, J., Altman, D. and The PRISMA Group (2009) Preferred Reporting Items for Systematic Reviews and Meta-Analyses: The PRISMA Statement. International Journal of Surgery, 8, 336-341. http://www.journal-surgery.net/article/S1743-9191(10)00040-3/pdf

[22] Allen, S., Chiarella, M. and Homer, C. (2010) Lessons Learned from Measuring Safety Culture: An Australian Case Study. Midwifery, 26, 497-503. http://dx.doi.org/10.1016/j.midw.2010.07.002

[23] Lawton, R., Gardner, P. and Plachcinski, R. (2010) Using Vignettes to Explore Judgements of Patients about Safety and Quality of Care: The Role of Outcome and Relationship with the Care Provider. Health Expectations, 14, $296-306$. http://dx.doi.org/10.1111/j.1369-7625.2010.00622.x

[24] Gephart, S.M., McGrath, J.M. and Effken, J.A. (2011) Failure to Rescue in Neonatal Care. The Journal of Perinatal \& Neonatal Nursing, 25, 275-282. http://dx.doi.org/10.1097/JPN.0b013e318227cc03

[25] Kfuri, T.A., Morlock, L., Hicks, R. and Shore, A.D. (2008) Medication Errors in Obstetrics. Clinics in Perinatalogy, 35, 101-117. http://dx.doi.org/10.1016/j.clp.2007.11.015

[26] Scholefield, H. (2007) Embedding Quality Improvement and Patient Safety at Liverpool Women’s NHS Foundation Trust. Best Practice \& Research Clinical Obstetrics \& Gynaecology, 21, 593-607. http://dx.doi.org/10.1016/j.bpobgyn.2007.02.005

[27] Simpson, K.R., James, D.C. and Knox, E.G. (2006) Nurse-Physician Communication during Labor and Birth: Implica- 
tions for Patient Safety. Journal of Obstetric, Gynecologic, \& Neonatal Nursing, 35, 547-556. http://dx.doi.org/10.1111/j.1552-6909.2006.00075.x

[28] Symon, A.G., McStea, B. and Murphy-Black, T. (2006) An Exploratory Mixed-Methods Study of Scottish Midwives’ Understanding and Perceptions of Clinical Near Misses in Maternity Care. Midwifery, 22, 125-136. http://dx.doi.org/10.1016/j.midw.2005.05.005

[29] Martijn, L., Jacobs, A., Amelink-Verburg, M., Wentzel, R., Buitendijk, S. and Wensing, M. (2013) Adverse Outcomes in Maternity Care for Women with a Low Risk Profile in the Netherland: A Case Serious Analysis. BMC Pregnancy and Childbirth, 13, 219. http://dx.doi.org/10.1186/1471-2393-13-219

[30] Currie, L. and Richens, Y. (2009) Exploring the Perceptions of Midwifery Staff about Safety Culture. British Journal of Midwifery, 17, 783-790. http://dx.doi.org/10.12968/bjom.2009.17.12.45548

[31] Barach, P. and Small, S.D. (2000) Reporting and Preventing Medical Mishaps: Lessons from Non-Medical near Miss Reporting Systems. BMJ, 320, 759. http://dx.doi.org/10.1136/bmj.320.7237.759

[32] Delmar, C. (2012) The Excesses of Care: A Matter of Understanding the Asymmetry of Power. Nursing Philosophy, 13, 236-243. http://dx.doi.org/10.1111/j.1466-769X.2012.00537.x

[33] Amsrud, K., Lyberg, A. and Severinsson, E. (2015) Evaluation of Nursing Students' Views of Improved Competence Development after Attending Clinical Supervision: An Educative Approach to the WHO Patient Safety Model. Open Journal of Nursing, 5, 725-734. http://dx.doi.org/10.4236/ojn.2015.58075

[34] Amsrud, E., Lyberg, A. and Severinsson, E. (2015) The Influence of Clinical Supervision and Its Potential for Enhancing Patient Safety-Undergraduate nursing Students' Views. Journal of Nursing Education and Practice, 5, 87-95. http://dx.doi.org/10.5430/jnep.v5n6p87

[35] Berggren, I. and Severinsson, E. (2003) The Nurse Supervisors' Actions in Relation to Decision-Making and Their Ethical Approach in Clinical Nursing Supervision. Journal of Advanced Nursing, 41, 615-622. http://dx.doi.org/10.1046/j.1365-2648.2003.02573.x

[36] Lyberg, A. and Severinsson, E. (2010) Midwives' Supervisory Styles and Leadership Role as Experienced by Norwegian Mothers in the Context of Fear of Childbirth. Journal of Nursing Management, 18, 391-399. http://dx.doi.org/10.1111/j.1365-2834.2010.01083.x

[37] Berggren, I., Bégat, I. and Severinsson, E. (2002) Australian Clinical Nurse Supervisors' Ethical Decision-Making Style. Nursing \& Health Sciences, 4, 15-23. http://dx.doi.org/10.1046/j.1442-2018.2002.00096.x

[38] Entwistle, V.A. and Watt, I.S. (2013) Treating Patients as Persons: A Capabilities Approach to Support Delivery of Person-Centered Care. The American Journal of Bioethics, 13, 29-39. http://dx.doi.org/10.1080/15265161.2013.802060

[39] Bélanger, L. and Ducharme, F. (2015). Narrative-Based Educational Nursing Intervention for Managing Hospitalized Older Adults at Risk for Dilerium: Field Testing and Qualitative Evaluation. Geriatric Nursing, 36, 40-46. http://dx.doi.org/10.1016/j.gerinurse.2014.10.010

[40] Bird, D. (2005) Patient Safety: Improving Incident Reporting. Nursing Standard, 14, 43-46. http://dx.doi.org/10.7748/ns2005.12.20.14.43.c4027

[41] Rooks, J. (1999) The Midwifery Model of Care. Journal of Nurse-Midwifery, 44, 370-374. http://dx.doi.org/10.1016/S0091-2182(99)00060-9

[42] Homer, C., Brodie, P. and Leap, N. (2008) Midwifery Continuity of Care-A Practical Guide. Elsevier, Chatswood.

[43] Sandall, J. (1997) Midwives’ Burnout and Continuity of Care. British Journal of Midwifery, 5, 106. http://dx.doi.org/10.12968/bjom.1997.5.2.106

[44] Correa-Velez, I. and Ryan, J. (2012) Developing a Best Practice Model of Refugee Maternity Care. Women and Birth, 25, 13-22. http://dx.doi.org/10.1016/j.wombi.2011.01.002

[45] Sandall, J., Soltani, H., Gates, S., Shennan, A. and Devane, D. (2008) Midwife-Led versus Other Models of Care for Childbearing Women. The Cochrane Collaboration, Issue No. 9., Wiley.

[46] Homer, C. Davis, G., Brodie, P., Sheehan, A., Barclay, L., Wills, J. and Chapman, M. (2001) Collaboration in Maternity Care: A Randomised Controlled Trial Comparing Community-Based Continuity of Care with Standard Hospital Care. British Journal of Obstetrics and Gynaecology, 108, 16-22. http://dx.doi.org/10.1016/s0306-5456(00)00022-X

[47] Waldenström, U. and Turbull, D. (1998) A Systematic Review Comparing Continuity of Care with Standard Maternity Services. British Journal of Obstetrics and Gyneacology, 105, 1160-1170. http://dx.doi.org/10.1111/j.1471-0528.1998.tb09969.x

[48] McCormack, B. and McCance, T. (2006) Development of a Framework for Person-Centred Nursing. Journal of Advanced Nursing, 56, 472-479. http://dx.doi.org/10.1111/j.1365-2648.2006.04042.x

[49] Vincent, C. (2003) Understanding and Responding to Adverse Events. The New England Journal of Medicine, 348, 
1051-1056. http://dx.doi.org/10.1056/NEJMhpr020760

[50] Ofstad, H. (1961) An Inquiry into the Freedom of Decision. Norwegian Universities Press, Oslo.

[51] Moore, J.E., Low, L.K., Titler, M.G., Dalton, V.K. and Sampselle, C.M. (2014) Moving toward Patient-Centered Care: Women's Decisions, Perceptions, and Experiences of the Induction of Labor Process. Birth, 41, 138-146. http://dx.doi.org/10.1111/birt.12080

[52] Barry, M.J. and Edgman-Levitan, S. (2012) Shared Decision Making - The Pinnacle of Patient-Centered Care. The New England Journal of Medicine, 366, 780-781. http://dx.doi.org/10.1056/NEJMp1109283

[53] Moore, J.E., Titler, M.G., Kane Low, L., Dalton, V.K. and Sampselle, C.M. (2015) Transforming Patient-Centered Care: Development of the Evidence Informed Decision Making through Engagement Model. Women's Health Issues, 25, 276-282. http://dx.doi.org/10.1016/j.whi.2015.02.002

[54] Higgens, J. and Green, S. (2005) Cochrane Handbook for Systematic Reviews of Interventions. The Cochrane Collaboration. http://handbook.cochrane.org/

[55] Scholefield, H. (2005) Risk Management in Obstetrics. Current Obstetrics \& Gynaecology, 15, 237-243.

[56] Maeda, S., Kamishiraki, E. and Sarkey, J. (2012) Patient Safety Education at Japanese Medical Schools: Results of a Nationwide Survey. BMC Research Notes, 5, 226. http://www.biomedcentral.com/1756-0500/5/226 http://dx.doi.org/10.1186/1756-0500-5-226 